\title{
SEGUNDAS JORNADAS DE INVESTIGACIÓN DE LA FACULTAD DE CIENCIAS SOCIALES UNIVERSIDAD DE COSTA RICA
}

\author{
SECOND RESEARCH SYMPOSIUM \\ OF THE FACULTY OF SOCIAL SCIENCES, \\ UNIVERSITY OF COSTA RICA
}

\author{
Dr. Manuel Martínez Herrera \\ Ex Decano Facultad de Ciencias Sociales (2015-2019) \\ Universidad de Costa Rica
}

La Facultad de Ciencias Sociales de la Universidad de Costa Rica está conformada por ocho Escuelas, a saber: Antropología, Ciencias Políticas, Comunicación Colectiva, Geografía, Historia, Psicología, Sociología y Trabajo Social que imparten a nivel de grado las correspondientes carreras y énfasis; además de los Institutos de Investigaciones Psicológicas y el Instituto de Investigaciones Sociales. Así mismo, existe una alianza estratégica con el Centro de Investigaciones Antropológicas (CIAN), el Centro de Investigaciones en Comunicación (Cicom), el Centro de Investigaciones y Estudios Políticos (CIEP) y el Centro de Investigaciones Históricas de América Central (CIHAC). De igual manera, las unidades académicas de la Facultad de Ciencias Sociales se encuentran asociadas a los Posgrados de: Antropología, Ciencias Políticas, Comunicación, Estudios de la Mujer, Geografía, Historia, Psicología, Sociología, Trabajo Social y Evaluación de Programas y Proyectos de Desarrollo (compartido) a nivel de maestría. Se cuenta también con los Doctorados de Ciencias Sociales sobre América Central y de Gobierno y Políticas Públicas (compartido).

La Facultad de Ciencias Sociales ha mantenido una amplia incidencia a lo largo de sus 45 años de existencia en las denominadas áreas sustantivas del quehacer universitario, esto es: la docencia la investigación y la acción social. En la actualidad cuenta con 7800 estudiantes regulares que cursan carreras propias de la Facultad en la Sede Rodrigo Facio, adicionalmente, existen las carreras desconcentradas de esta Facultad en las diferentes sedes universitarias, teniendo de esta manera una amplia cobertura a nivel nacional. Por otra parte, se encuentran debidamente inscritos 236 proyectos en la Vicerrectoría de Investigación y 80 proyectos en la Vicerrectoría de Acción Social entre actividades de extensión docente, cultural $y$ trabajo comunal universitario ${ }^{1}$.

En el año 2017 se realizaron las Primeras Jornadas de Investigación de la Facultad de Ciencias Sociales, con 72 ponencias y más de 100 expositores y expositoras provenientes de todas las escuelas, centros e institutos de investigación de la Facultad, con el fin de mostrar y mostrarnos qué, cómo, dónde y con quién se estaba investigando. Gracias al éxito alcanzado se decide realizar dos años después las Segundas Jornadas de Investigación de la Facultad de Ciencias Sociales. Dichas Jornadas se realizaron durante el mes de abril del presente año, con la participación de 80 investigaciones y más de un centenar de expositores y expositoras de todas las unidades académicas presentes en la Facultad. 
Los trabajos presentados versaron acerca de variadas temáticas disciplinarias y líneas de investigación, tales como: derechos humanos, género, políticas públicas, comunicación social, subjetividades, culturas autóctonas, ambiente y naturaleza y salud entre otros.

La presente publicación es una muestra significativa del acervo y el quehacer académico de Facultad, del conjunto de experiencias acumuladas a lo largo de décadas de docencia, investigación y acción social, de las preocupaciones y demandas históricas y coyunturales que como sociedad acometemos; así como de los nuevos emprendimientos teóricos y metodológicos que sin lugar a dudas desafían nuestros campos disciplinarios. Es una posibilidad de indagar en el vasto campo de las ciencias sociales, como una manera de entender los propios límites y visualizar las oportunidades de desarrollo que brinda el trabajo multidisciplinario y multiparadigmático.

Nuestro agradecimiento imperecedero a la Revista de Ciencias Sociales de la Universidad de Costa Rica por permitirnos compartir con la comunidad académica nacional e internacional, a través de su vasta red de lectoras y lectores nuestra producción académica, ratificando una vez más, la profunda y fecunda relación que tradicionalmente ha existido entre esta estimada Revista y nuestra Facultad. 